\title{
El "perímetro de lo insignificante". Paradigma indiciario y el problema de la atención en la modernidad
}

\author{
Hugo Herrera Pardo \\ Pontificia Universidad Católica de Valparaíso
}

\begin{abstract}
«¿Quién construyó Tebas de las siete puertas?» pregunta el lector obrero de Brecht. Las fuentes nada nos dicen de aquellos albañiles anónimos, pero la pregunta conserva toda su carga.

C. Ginzburg, "Prefacio" a El queso y los gusanos
\end{abstract}

Sobre la superficie solo en apariencia exterior de los márgenes se inscriben los límites necesarios que la institución esgrime para constituir y asegurar la inmanencia de su legado, la economía de valores que decide lo que entra y lo que queda fuera de su archivo.

Julio Ramos, "Las paradojas del deseo de Flora Tristán"

\section{I}

La experiencia de un "giro materialista" presente desde hace varias décadas en disciplinas como la Historia, la Sociología de los textos, la Historia de las ideas o los Estudios Literarios y Culturales, nos ha hecho reflexionar no solo en torno a una persistente escisión moderna entre "idealismo" y "materialismo", disciplinas "platónicas" y "pragmáticas" o entre "materialidad del texto" y "textualidad del libro", expresiones acuñadas y explicadas por Roger Chartier (Inscribir y borrar 10-11) a partir de procesos ligados al neoplatonismo, la Estética o la definición del Copyright, sino también respecto de una especie de "perímetro de lo insignificante" al que fueron relegados diversos modos de subjetivación y manifestaciones socioculturales por no haber sido considerados fuentes, objetos o temas de estudio tradicionales. Tomo prestada aquella expresión -"perímetro de lo insignificante"- de Iván de los Ríos, quien en la apertura de su estudio introductorio al texto Elogio de la calvicie de Sinesio de Cirene (370 d.c-413/4 d.c), y ante la constatación de los "rangos, elencos y jerarquías" que organizan y distribuyen lo que adquiere estatuto filosófico o no, se interroga por una "genealogía filosófica de lo insignificante" para examinar el núcleo de problemas que legitimaría a los objetos que cumplen con las condiciones establecidas por el conocimiento científico, merecedores por tanto, y al menos en apariencia, de "elucidación intelectual". Ante tal pregunta, y desde un planteamiento discursivo que se posiciona de lado de las escrituras en torno a lo nimio y trivial eclipsadas por el gran relato de la filosofía occidental, como el Elogio a la cabellera de Dión 
de Prusa, el Panegírico del ratón de Polícrates o los elogios a las moscas y los parásitos de Luciano de Samosata, De los Ríos señala:

En líneas generales, el proyecto filosófico de Occidente permite aislar con precisión aquellos conceptos que designan los aspectos secundarios, coyunturales y marginales de lo real a partir de una propuesta metafísica y epistemológica centrada en las coordenadas de la inmutabilidad, la eternidad, la estabilidad y la permanencia. Existe, pues, un perímetro de lo insignificante. La realidad que merece ser cuestionada e interrogada es aquella que no está sometida a los avatares del tiempo y la cotidianidad, la indeclinable (...) Toda región susceptible de atención filosófica cuyas características no suscriban estos rasgos históricamente asentados pertenece, por tanto, al ámbito residual de lo insignificante (12)

La tesis diferencial de la lingüística y sus alcances nos han persuadido que los valores son relacionales, que aquello que "está más allá del límite de exclusión implica la imposibilidad de lo que está de este lado del límite" (Laclau 72). In-significante es, de modo literal, aquello que aún no ha sido investido como signo, aquello que ha sido negado o privado (aún) de significar. Línea divisoria que instaura una tensión permanente entre ley y legitimidad, entre aquello que ha sido autorizado como legible y aquello a lo que le ha sido reprimida tal condición. Para el caso de la filosofía, De los Ríos sostiene en su argumentación que "una propuesta metafísica y epistemológica centrada en las coordenadas de la inmutabilidad, la eternidad, la estabilidad y la permanencia" habría dibujado el límite legal que asigna el juego de posiciones entre lo que es significante y lo que no.

Por tanto, la imagen-concepto sugerida por De los Ríos para el caso de la filosofía puede ser extensible a casi todo el amplio espectro de las Humanidades y Ciencias Sociales, las que, desde las últimas décadas del siglo pasado y emplazadas ante la pregunta por los límites de la identificación y demarcación de sus objetos de estudio, han incorporado otras formas de subjetividades, textualidades y prácticas discursivas al ámbito de sus saberes disciplinarios. Objetos de atención defendidos y profundizados por los Estudios Culturales, la Microhistoria o la Microsociología son solo algunos casos notorios de cómo, durante la segunda mitad del siglo pasado, fueron sometidos a examen cánones establecidos, "tradiciones selectivas" (a decir de Raymond Williams) y repertorios consolidados, hasta el punto de eclosionar sus versiones largamente estabilizadas. Un litigio de alcances históricos, éticos y políticos que en muchas ocasiones avanzó hasta un cuestionamiento material de las condiciones de conocimiento y hasta a un emplazamiento de la posición social de los investigadores, porque a fin de cuentas este cercado perimetral demuestra que a la operación de estabilizar significados le es inherente el establecimiento de una topología social.

Pero, justo allí, tras asumir su imagen-concepto y atender a su respuesta, surgen otras preguntas, esta vez de carácter más general: ¿qué condiciones y coacciones trazan los límites del "perímetro de lo insignificante" que, en la 
producción de conocimiento, recorta objetos, temas, métodos y problemas, así como define posiciones y establece jerarquías dentro de las instancias de subjetivación propugnadas por la construcción de saberes? ¿Mediante qué estrategias de autorización -las que, paralelamente y en contrapartida, serían siempre "estrategias de impugnación"- los saberes constituyen sus campos, en los que, a la vez, los investigadores intentarían validarse? Y otra, ¿qué condiciones permiten, en ciertos casos, que investigadores subviertan estos modos de validación al intentar inscribir dentro del campo elementos que habían permanecido impugnados, es decir, habían sido posicionados tras la línea que demarca el "perímetro de lo insignificante"?

Sin dejar de reconocer lo sobredeterminado del asunto junto con sus múltiples factores y explicaciones genealógicas, mi objetivo en lo que sigue es plantear una respuesta general a estos problemas, tratando de profundizar en ciertos modos tanto de conformación como de crisis, así como en algunas estrategias de exclusión y silenciamiento de aquel "perímetro de lo insignificante", retomando una disquisición anterior acerca de la literatura vestigial ${ }^{1}$, y a partir de una reflexión guiada por algunos textos de Carlo Ginzburg, como El queso y los gusanos -en el marco de la celebración de los cuarenta años desde que fue publicado- pero también aquellos en los que propone y examina el surgimiento de lo que hacia fines de la década del setenta denominó "paradigma indiciario" para pensar los niveles teóri$\mathrm{Co}$, histórico y hasta autobiográfico de su propio oficio de historiador ${ }^{2}$. Me refiero en concreto a ensayos como el célebre "Huellas. Raíces de un paradigma indiciario"3, pensado y escrito en las proximidades a la publicación de El queso y los gusanos, "Reflexiones sobre una hipótesis: el paradigma indiciario, veinticinco años después" y "Semejanzas de familia y árboles de familia: dos metáforas cognoscitivas". Paradigma del que, como se sabe, luego omitió referirse por más de un cuarto de siglo (ello, como él mismo

\footnotetext{
1 Me refiero al volumen Vestigio y especulación. Textos anunciados, inacabados y perdidos de la literatura chilena, editado junto con Jorge Cáceres y Nibaldo Acero. Por vestigio o literatura vestigial comprendí en aquel momento una singular noción de materialidad, pensada desde sus resquicios, para someter a examen un proyecto que había sido abortado ya sea en la producción, circulación o distribución del libro. Definí a vestigio entonces como "una manifestación cuya materialidad ha sido -incidental o voluntariamente- fracturada o abortada, pero cuyo sentido, por medio de redes de asociación, puede de algún modo llegar a interpretarse, es decir, a especularse". La hipótesis más general que articulada a ese proyecto es que, tras ese quiebre, tras aquella manifestación que no llega completamente a producirse, circularse o distribuirse, subyacen todo un conjunto de coacciones que encaran los fundamentos de las diversas prácticas culturales.

2 Carlo Ginzburg reconoce y señala explícitamente este triple nivel que atravesó su polémico ensayo de 1978 en su texto "Reflexiones sobre una hipótesis: el paradigma indiciario, veinticinco años después".

3 Como se sabe, "Spie. Radici di un paradigma indiciario" es un título que, aparte de polémico, es polisémico (la palabra italiana spie significa, a la vez, tanto indicios como espías), lo que ha suscitado que lo relativo a las traducciones del ensayo, junto con sus distintas versiones, sean un tema a considerar. Acerca de la polisemia del vocablo italiano "spie", las traducciones y versiones del ensayo alrededor del mundo y, en específico, sus traducciones y versiones en español, remito a las lectoras y lectores al artículo de Carlos Aguirre Rojas "Indicios, lecturas indiciarias, estrategia indiciaria y saberes populares. Una hipótesis sobre los límites de la racionalidad burguesa moderna". En lo personal, me interesa sobre todo la publicación del ensayo de Ginzburg bajo el título de "Morelli, Freud y Sherlock Holmes: indicios y método científico", debido a razones que especificaré más adelante.
} 
aclaró, no significó que durante ese tiempo no haya seguido desarrollando algunas de sus implicaciones), debido al fastidio producido por las enconadas polémicas a las que su célebre ensayo dio paso.

Por medio de esta comprensión paradigmática, que él sitúa como emergente hacia la década de 1870-1880, Ginzburg también entiende el valor hermenéutico proscrito que subyace a los márgenes, lo que puede llegar a leerse como síntoma reprimido e instalado como frontera, debido a que efectivamente el historiador italiano reconoce que se trata de un paradigma que basándose en la sintomatología es que comienza a afirmarse en las ciencias humanas. Es así como en su ensayo "Semejanzas de familia y árboles de familia" consigna

"Porque creo que la relación entre normas y elementos de transgresión es -por lo menos desde un punto de vista cognoscitivo-, una relación asimétrica. Ninguna norma es capaz de predecir el entero abanico de sus posibles elementos transgresores o de sus transgresiones; mientras que, en cambio, esos elementos transgresores o transgresiones, y las anomalías, siempre implican a la norma, y por lo tanto nos obligan a tomarla necesariamente en cuenta. De modo que es esta la razón por la cual, una estrategia de investigación basada en contornos difusos, en errores y en anomalías, me parece potencialmente mucho más promisoria y gratificante".

"Elementos transgresores", "anomalías", "desviaciones diferenciales". O también "elementos poco apreciados o inadvertidos, en los detritus y desechos de nuestra observación" (101), de acuerdo con una frase de Freud rescatada por Carlo Ginzburg en el reconocido escrito "Huellas. Raíces de un paradigma indiciario". En este mismo ensayo el italiano referirá a los saberes tras estas formas como "la capacidad de remontarse desde datos experimentales aparentemente omitibles hasta una realidad compleja no directamente experimentada" (108). A partir de esta cita puede comprenderse por qué Ítalo Calvino en su comentario acerca de este ensayo definirá a estos elementos como la "idea de una legibilidad no inmediata" (66). Todas estas formas de nombrar lo nimio apuntan a manifestaciones que logran evadir el perímetro, de "contornos difusos", que demarcan el espacio de lo significante $-y$, a su vez, de lo significativo- para convertirse en examinadoras de las normas que convencionalmente fijan los modos de la legalidad: leyes y legados.

\section{II}

Mi manera de aproximarme a lo propuesto como objetivo, le hace un guiño a uno de los modos de lectura que Ginzburg reconoce en ese "desgraciado caído en desgracia del mundo" (El queso y los gusanos 202) que es Menocchio, según él mismo se define en un documento redactado antes de que lo llevaran a la cárcel por segunda vez. El historiador nos dice del molinero friuliano que algunas de sus claves de lectura, lo que Ginzburg denomina "tamiz", consistían en contrastar textos, aislar pasajes, plantear analogías. De modo similar propondré leer el exitoso y polémico ensayo de Ginzburg "Huellas. 
Raíces de un paradigma indiciario", también conocido como "Morelli, Freud y Sherlock Holmes: indicios y método científico"4, traducción que guarda más sentido con lo que intentaré proponer, a partir del contraste con el ensayo de Michel Foucault "Nietzsche, Freud, Marx" (1967). Por supuesto que esta lectura contrastiva se funda en los efectos de la lectura de ambos textos y no en las condiciones de producción del ensayo de Ginzburg. Como se puede apreciar, no se trata de una referencia citada por el historiador italiano en su texto, aunque sí aparece en él una brevísima referencia a un trabajo de Foucault, el que es La microfísica del poder. Más bien lo que propongo en este sentido es leer el ensayo de Ginzburg como una extensión del debate abierto por este respecto de los primeros libros de Michel Foucault, en específico aludo a la confrontación que es explícita en el apartado cinco del "Prefacio" a El queso y los gusanos, en donde Ginzburg refiere críticas a Historia de la locura, Las palabras y las cosas, La arqueología del saber y, sobre todo, a Yo, Pierre Riviere... en tanto que, a juicio de Ginzburg, lo que en aquellos trabajos interesa a Foucault son más "los gestos y criterios de la exclusión; los excluidos menos" (20). En dicho juicio se advierte tanto a nivel de escala como de proceso las disensiones que hacen discrepar al historiador italiano respecto de las propuestas del filósofo francés en torno al estudio de las formas culturales subalternas. A Foucault le interesan más los criterios de formación de tecnologías, lenguajes y estrategias, mientras que a Ginzburg le interesan prioritariamente las condiciones históricas de los procesos de subjetivación a partir de desviaciones significativas y diferenciales.

De este modo, en "Morelli, Freud y Sherlock Holmes" y en "Nietzsche, Freud, Marx", las propuestas de Ginzburg y Foucault vuelven a intersectarse conflictivamente. Ambos ensayos coinciden en una importante transformación para el pensamiento occidental que se condensa textualmente hacia fines del siglo XIX. El filósofo francés denomina a este hito un cambio en las "técnicas o sistemas de interpretación", mientras que para el historiador italiano esta transformación consiste en el surgimiento silencioso de un modelo epistemológico o paradigma. La discrepancia a nivel de escala entre ambos autores se encuentra cifrada en esa trayectoria silenciosa atribuida por Ginzburg a dicho proceso. Mientras que para Foucault la transformación en las técnicas de interpretación modernas se cristaliza en las tres grandes referencias del pensamiento de la sospecha y en específico algunos de sus más destacados trabajos como el primer libro de El Capital para el caso de Marx, El nacimiento de la tragedia y La genealogía de la moral de Nietzsche y La interpretación de los sueños de Freud, para el historiador italiano las figuras en las que puede percibirse la emergencia de un "paradigma indiciario" son un polémico historiador del arte italiano que compuso un singular método basado en el reconocimiento de los lóbulos de las orejas, las uñas, la forma de los dedos de las manos y de los pies para establecer atribuciones de pinturas de dudosa autoría (Giovanni Morelli), un personaje de ficción que fue un inconmensurable fenómeno popular hacia fines de siglo XIX y comienzos del XX (Sherlock Holmes) y un Freud distinto al considerado por

\footnotetext{
4 Con este título, y en español, se puede encontrar este ensayo en el volumen compilado por Umberto Eco y Thomas Sebeok. El signo de los tres. Barcelona: Lumen, 1989, aparecido originalmente en 1983.
} 
Foucault; un Freud que reconoce en algunas de sus cartas (documentos de la intimidad, es decir considerados con un estatuto "insignificante" respecto de las obras mayores del fundador del psicoanálisis) que un singular historiador del arte cuyo seudónimo Lermolieff era una anagrama de su verdadero apellido Morelli, como una de las influencias en su concepción de la corriente psicoanalítica.

Si esto ocurre a nivel de escala, a nivel de proceso la diferencia es aún más notoria. Las transformaciones de los sistemas de interpretación en Foucault se condensan en un tiempo histórico que va principalmente desde el siglo XVI hasta el XIX, con algunas menciones significativas al período helénico. Por el contrario, el trayecto histórico ensayado por Ginzburg no solo es inmensamente más amplio, proponiendo un recorrido desde el neolítico hasta fines del siglo XIX y relacionando procesos sociales atravesados por transformaciones como la invención de la escritura, la invención de la imprenta o la emergencia de tecnologías disciplinarias en las sociedades decimonónicas, sino que también excede espacialmente la geografía europea, haciendo referencia a otras latitudes y períodos históricos como el de Babilonia o la India colonial. Mostrando en los momentos seminales de este recorrido cómo el "cuerpo, el lenguaje y la historia de los hombres fueron sometidos por primera vez a una indagación desprejuiciada, que excluía por principio la intervención divina" ("Huellas" 113). Sin embargo, llegados a este punto el contraste a nivel de escala se agudiza, ya que los implicados en el plano de las subjetividades no solo son Morelli, Sherlock Holmes y el joven Freud frente a Nietzsche, Marx y el Freud maduro, sino que también el ensayo de Ginzburg rescata la experiencia histórica de cazadores neolíticos, adivinos babilonios, paleógrafos romanos del siglo XVI, funcionarios de la administración inglesa en la India a fines del siglo XIX, escritores de ficción, sobre todo policial, desde mediados del siglo XVIII.

A este respecto, en términos de historización de subjetividades significativas y diferenciales, el trabajo de Ginzburg también viene a cuestionar la tesis que solventa el ensayo de Foucault en cuestión. Dicha tesis establece que durante el siglo XVI la técnica de interpretación, basada en un sistema orgánico de semejanzas, consistía en que

los signos se disponían de una manera homogénea en un espacio que era también homogéneo, y esto en todas las direcciones. Los signos de la tierra reenviaban al cielo, pero reenviaban también al mundo subterráneo, reenviaban del hombre al animal, del animal a la planta, y recíprocamente. A partir del siglo XIX (Freud, Marx y Nietzsche), los signos se han sobrepuesto en un espacio mucho más diferenciado, según una dimensión que se podría llamar de profundidad, pero a condición de no entender por ella la interioridad sino, al contrario, la exterioridad (143).

El caso de Menocchio comentado y analizado por Ginzburg perturba la tesis de Foucault respecto del espacio homogéneo de interpretación que habría predominado desde el siglo XVI. Las alucinantes opiniones de Menocchio acerca del parasitismo del clero, el rechazo del Evangelio o la negación de 
la divinidad de Cristo, explicadas por el historiador italiano a partir de una particular circulación cultural, conflictiva entre lo oral y lo letrado y experimentada por las clases subalternas de la Europa preindustrial, obstruyen ese espacio homogéneo pensado por el filósofo francés, presentando por medio de Menocchio (siendo posible pensar que algo similar ocurría con aquel Pighino o Marco o Marcato que aparecen mencionados hacia el final de El queso y los gusanos, entre tantos otros que "vivieron y murieron sin dejar huellas", la cursiva es mía) un espacio de repartición transgredido, en el que la producción normada de lo inteligible se encuentra intervenida por singulares procesos de subjetivación no encontrándose, por tanto, del todo supeditado a estructuras históricas.

\section{III}

Hasta acá, el contraste entre los ensayos en cuestión de Foucault y Ginzburg nos ha valido para constatar el momento de emergencia en el que comenzaron a operar algunas transformaciones en el espacio de repartición, el "reparto de lo sensible" a decir de Jacques Rancière (El desacuerdo), que posibilita contornear algo así como un "perímetro de lo insignificante". Debemos pensar ahora en algunas de sus condiciones y coacciones. Para ello resulta elocuente recuperar una vez más la frase que Ginzburg toma de Freud: "elementos poco apreciados o inadvertidos, en los detritus y desechos de nuestra observación". Lo que esta frase nos transmite es que no solo la experiencia de un "giro materialista" nos ha hecho posicionar nuestro interés frente a un espacio de repartición en el que queda trazado un "perímetro de lo insignificante". Dicha frase nos señala que también la experiencia de un "giro visual" ha tomado un rol relevante en dicho asunto. Incluso debemos reconocer que un tercer "giro" resulta asociado de manera consustancial a estos dos, mediante la metáfora del "perímetro"; me refiero al "giro espacial". Los tres "giros" se encuentran estrechamente imbricados en sus condiciones y efectos, de modo que cada uno inevitablemente acaba retrotrayendo a los otros $^{5}$. $Y$ en sus cruces e interacciones, los tres nos posicionan frente a temas centrales que atraviesan los ensayos tanto de Foucault como de Ginzburg, siendo algunos de ellos la crisis del modelo occidental de racionalidad y de la categoría europea de totalidad, la crisis experimentada por la palabra a partir de la conformación de lenguajes matemáticos desde el siglo XVII o el desarrollo y los avatares de la idea moderna de signo comenzando en los gramáticos de Port Royal hasta Pierce y Saussure. Las preguntas ligadas a

\footnotetext{
5 Sin lugar a dudas que resulta problemático usar indistintamente tanto "paradigma" como "giro". Aunque el reconocimiento de esa zona de indistinción algo nos señala respecto de que habrían, entre ambos conceptos, significaciones compartidas, así como también otras que los singularizarían y, por tanto, ejercerían en ellos cierta distancia. Sin estar en condiciones de poder establecer esta similaridad/distinción de manera tan desarrollada, me atreveré a decir que lo que causaría algo así como el efecto de sinonimia entre ambos es, siguiendo en esto una tesis de Agamben respecto de "paradigma", su capacidad como forma de conocimiento analógica que así pasaría a neutralizar "la dicotomía entre lo general y lo particular", sustituyendo de este modo "la lógica dicotómica por un modelo analógico bipolar" (42). Mientras que uno de los aspectos que mayormente los distanciaría sería la aparente percepción fenoménica de matriz disciplinar más formalizada para el caso de "paradigma", que lo llevaría a desplegar un movimiento que iría desde "la singularidad a la singularidad" (42), matriz y movimiento no tan explícitas en la idea de "giro".
} 
las condiciones y coacciones del "perímetro de lo insignificante", entonces, pueden ser respondidas en una aproximación general si atendemos a la explicación por aquellos "elementos poco apreciados o inadvertidos, en los detritus y desechos de nuestra observación", a partir de la transformación de la naturaleza de la visualidad acontencida durante el período moderno. Un problema que se encuentra en un estado de silenciamiento en los trabajos de Ginzburg y Foucault comentados en el apartado anterior, aunque luego el francés lo haya circundado en algunos trabajos 6 y Ginzburg merodeado en un ensayo posterior que, a mi juicio, es en cierto sentido una continuación de "Huellas" (recordemos a este punto el estado inacabado del texto), me refiero a "Semejanzas de familia y árboles de familia: dos metáforas cognitivas" (2004).

Desde la década de los noventa contamos con nutridas aproximaciones al fenómeno de transformación de la naturaleza de lo visual acontecida en la modernidad y sus implicaciones en el problema de la atención, a partir de investigaciones plasmadas en libros como Las técnicas del observador. Visión y modernidad en el siglo XIX y Suspensiones de la percepción. Atención, espectáculo y cultura moderna, ambos de Jonathan Crary, o el libro de Martin Jay Ojos abatidos. La denigración de la visión en el pensamiento francés del siglo $X X$. Por ejemplo, la tesis central presentada por Crary en el primero de los libros referidos es que, desde principios del siglo XIX, un conjunto de relaciones que involucraban tanto al cuerpo como al poder institucional $y$ discursivo, redefinieron el estatus del sujeto observador a partir de la emergencia de una serie de dispositivos ópticos (entre ellos el estereoscopio que, de paso, Ginzburg analiza en "Semejanzas de familia...") que condujeron a una profunda reorganización del conocimiento y de las prácticas sociales, modificando de múltiples maneras las capacidades productivas, cognitivas y deseantes del sujeto humano. Fenómeno que sin lugar a dudas intervino en los discursos filosóficos, literarios, técnicos y científicos, propiciando el espacio para la irrupción de lo insignificante, "aquellas formas de saber que tienden a ser mudas", las que, una vez advertidas, contribuyen a expandir el campo de lo inteligible, lo emergente y la diferencia. De acuerdo con Crary, lo que tiene lugar en el tramo temporal de unas tres décadas, aproximadamente desde 1810 hasta 1840, es lo que denomina "un desarraigo de la visión con respecto a las relaciones estables y fijas encarnadas por la cámara oscura":

Si la cámara oscura, en tanto concepto, subsistía como base objetiva de verdad visual, diversos discursos y prácticas -en filosofía, en ciencia y en los procedimientos de normalización social- tienden a abolir los fundamentos de esa base a principios del siglo XIX. En cierto sentido, lo que ocurre es una nueva valoración de la experiencia visual: se le da una movilidad e intercambiabilidad sin precedentes, abstraída de todo lugar o referente fundantes (32).

6 De tal modo que, como se verá más adelante, sirvió de base conceptual para los trabajos de Jonathan Crary que serán refereridos en lo sucesivo. 
De esta manera, el autor pasa a sostener que la experiencia visual perdió, durante el siglo XIX, "los privilegios apodícticos de que se valía la cámara oscura para imponer la verdad" (33). Así, para Crary, pero también para otros autores como Foucault, Jay o Baudrillard, lo que denominamos modernidad coincide con el desplome de los modelos clásicos de visión y su espacio estabilizado de representación. Nosotros tendríamos que decir de su espacio de repartición y distribución estable. Para estos autores, desde la primera mitad del siglo XIX, la observación se torna cada vez más una cuestión de sensaciones y estímulos equivalentes que no contienen referencia a una localización espacial específica7. Según lo plantea Jonathan Crary en Las técnicas del observador, lo que que se instala hacia la década de 1820 y 1830 es un reposicionamiento del observador "fuera de las relaciones fijas interior/ exterior que la cámara oscura presuponía y en un territorio no demarcado en el que la distinción entre sensación interna y signos externos se difumina irrevocablemente" (45). De este modo, para el autor, si "alguna vez hubo una «liberación» de la visión durante el siglo XIX, es entonces cuando sucede por primera vez. En ausencia del modelo jurídico de la cámara oscura, se produce una emancipación de la visión, un derrumbamiento de las rígidas estructuras que le habían dado forma y habían constituido sus objetos" (45). Llegado a este punto de su argumentación, Crary se apoya en Baudrillard para hacernos atender que:

la modernidad está estrechamente relacionada con la capacidad que las clases y las categorías sociales recién llegadas al poder tienen de superar «la exclusividad de los signos» y de promover «la proliferación de los signos según la demanda». Las imitaciones, las copias, las falsificaciones y las técnicas para producirlas (entre las que se encontrarían el teatro italiano, la perspectiva lineal y la cámara oscura) supusieron todas ellas desafíos al monopolio y control aristocrático de los signos. El problema de la mímesis aquí no es ya un problema de estética sino de poder social, un poder fundado en la capacidad de producir equivalencias (30).

\footnotetext{
7 Este punto puede ser complementado con lo que Anthony Giddens denomina como "desencajamiento del sistema social" ocasionado por la modernidad, al extraer las relaciones sociales de sus "contextos locales de interacción" y reestructurándolas mediante "cantidades indefinidas de espacio-tiempo" (Consecuencias de la Modernidad 21). De acuerdo con Giddens: "En las sociedades premodernas casi siempre coinciden el espacio y el lugar puesto que las dimensiones espaciales de la vida social, en muchos aspectos y para la mayoría de la población, están dominadas por la «presencia»-por actividades localizadas-. El advenimiento de la modernidad paulatinamente separa el espacio del lugar al fomentar las relaciones entre los «ausentes» localizados a distancia de cualquier situación cara-a-cara. En las condiciones de la modernidad el lugar se hace crecientemente fantasmagórico, es decir, los aspectos locales son penetrados en profundidad y configurados por influencias sociales que se generan a gran distancia de ellos" (Consecuencias de la modernidad 30)". Los avatares de estas "consecuencias de la modernidad", propuestas por Giddens, guardan mucho sentido con la transformación de la naturaleza de la visualidad estudiada por Crary, Jay y otros, y, en definitiva, refuerzan la idea del vínculo entre los "giros" espacial, visual y material.
} 
Es esta capacidad para producir equivalencias frente al "control aristocrático de los signos" a la que se enfrentaron Morelli, Freud y Sherlock Holmes, a fines del siglo XIX, y el propio Carlo Ginzburg sobre todo tras la publicación de El queso y los gusanos y la aparición de su polémico ensayo de 1978. Podemos decir que es esta capacidad para producir equivalencias una de las principales coacciones a las que se enfrenta el investigador que quiere alterar el espacio de distribución de los signos, trayendo hacia él lo que había sido con-signado como in-significante. Por tanto, es este estatuto de autonomía que adquiere la visión en el transcurso del siglo XIX, disociándose del tacto y desbaratando las condiciones de veridicción anteriores, lo que posibilita que los "detritus y desechos de nuestra observación" comiencen a ser considerados con cierta relevancia:

La disociación de tacto y vista que le sigue tiene lugar en el marco general de una «separación de los sentidos» y de una reconfiguración industrial del cuerpo que tiene lugar durante el siglo XIX. Una vez que el tacto dejó de ser un componente conceptual de la visión, el ojo se desligó de la red referencial encarnada en la tactilidad e inició una relación subjetiva con el espacio percibido. Esta autonomización de la vista, que tuvo lugar en diferentes ámbitos, fue una condición histórica para la reconstrucción de un observador hecho a la medida de las tareas del consumo «espectacular». El aislamiento empírico de la visión no solo posibilitó la cuantificación y homogeneización, sino que también permitió a los nuevos objetos de la visión (fueran mercancías, fotografías o el acto de percepción en sí mismo) asumir una identidad mistificada y abstracta, escindida de toda relación con la posición del observador dentro de un campo unificado cognitivamente. El estereoscopio es un lugar cultural de gran importancia en el que esta brecha entre la tangibilidad y la visualidad se hace particularmente evidente (39).

Esta transformación de la naturaleza de la visualidad nos conduce al problema de los cambios que experimentó la atención durante el período moderno. Tema explorado por Crary en su siguiente libro Suspensiones de la percepción. Para el autor, "la aparición de la atención como problema a finales del siglo diecinueve coincide con la organización específica de los sistemas de trabajo y producción en el capitalismo industrial" (39). Por tanto, la lógica cultural del capitalismo "nos fuerza a aceptar que desplazar nuestra atención rápidamente desde una cosa a otra es algo natural (38). Para Crary, el capital, entendido en su sentido más lato como un proceso de aceleración de transacciones, distribuciones y circulaciones, "produjo inevitablemente este tipo de adaptabilidad perceptiva humana reconvirtiéndose en un régimen de atención y distracción recíprocas" (38). De esta manera, y contrario a lo que ocurría con anterioridad en modelos de visión predominantes, "la movilidad, la novedad y la distracción se identificaban como elementos constitutivos de la experiencia perceptiva" (38). Así, desde fines del diecinueve, "la capacidad de dirigir la atención depende de la capacidad del observador para adaptarse a la continua reconfiguración de las formas de consumo del mundo 
sensorial" (41). En definitiva, a medida que se comienza a comprender al observador a base de la subjetividad esencial de la visión, la atención pasa paulatinamente a convertirse en un elemento que constituye, pero que a la vez desestabiliza, a la percepción. Son estas transformaciones en el campo de la atención las que le otorgan sentido a elementos como los lóbulos de las orejas, la forma de las uñas, las cenizas del cigarrillo o el inconsciente para que comiencen a ser considerados como transmisores de un tipo de saber, en campos como la Historia del arte, la novela policial o el (en aquel entonces) emergente Psicoanálisis. De acuerdo con Crary

La distracción y el olvido (que sugieren la sublimación y la represión) se convirtieron para Schopenhauer en poderosos componentes de la fluida economía de la experiencia psíquica. Todos los estados mentales que el pensamiento clásico había excluido o marginado en sus teorías del conocimiento (como el sueño, el trance, el desmayo, la ensoñación o la disociación) se convertían ahora en protagonistas de las explicaciones psicológicas de la subjetividad normativa. Dentro de un marco histórico más generalizado podemos observar la desintegración de una tradición epistemológica que va desde Descartes hasta Kant, para la que la conciencia o el cogito es el cimiento de toda certeza y conocimiento. El problema de la atención solo aparece cuando la conciencia deja de tener una prioridad fundacional indiscutible -cuando el sujeto deja de ser sinónimo de una conciencia que esencialmente se presenta ante sí misma, cuando ya no existe una congruencia inevitable entre la subjetividad y un «Yo» pensante- (63).

Este último aspecto señalado en la cita anterior guarda sentido, sobre todo, con la irrupción histórica del Psicoanálisis, no obstante sus alcances claramente exceden esta relación, extendiendo sus lazos de sentido hasta el examen de todo un modo de racionalidad considerado clásico dentro de la constitución de la ciencia moderna. Sin embargo, y como queda patente en las resistencias experimentadas por Morelli o Freud (mucho más que Sherlock Holmes, por supuesto, debido al campo en el que este último expone sus descubrimientos visuales) y hasta el mismo Carlo Ginzburg varias décadas después, estos cambios en el fenómeno de la atención no desde siempre tuvieron una consideración positiva de carácter inapelable. Como el mismo Crary menciona en su argumentación, a pesar "de la importancia de la atención en la organización y modernización de la producción y el consumo, la mayoría de los estudios sugerían que la atención convertía la experiencia perceptiva en algo inestable, continuamente sujeta a cambios y en último término, disipadora" (69). La consideración de este tema nos conduce hacia nuestras últimas interrogantes.

\section{IV}

La asunción de algunos efectos provocados por la transformación de la naturaleza de la visualidad durante el período moderno y sus correlatos 
en el campo de la atención, nos han ayudado a comprender la emergencia de ciertas condiciones y coacciones tras el "paradigma indiciario" de Carlo Ginzburg. Nos resta atender a las otras dos interrogantes que nos hemos planteado, las que guardan relación con las estrategias de autorización e impugnación que atraviesan a los saberes que logran constituir campos de investigación y, a la vez, validan a los investigadores, y también relativas a las condiciones que permiten, en ciertos casos, que investigadores subviertan estos modos de validación al intentar inscribir dentro del campo elementos que habían permanecido impugnados, es decir, habían sido posicionados tras la línea que demarca el "perímetro de lo insignificante".

Para ello volvamos a un enunciado que Ítalo Calvino vierte en el ensayo "Spie..." de Ginzburg; según el primero, el trabajo del último nos posiciona respecto de "la idea de una legibilidad no inmediata". Tras este enunciado se cifra la comprensión del "paradigma" que significarían las formas de saber venatorio defendidas por Ginzburg. ¿En qué momento, entonces, la legibilidad no inmediata comienza su proceso de validación frente a lo legible inmediato? En un pasaje del "Prefacio a la segunda edición en español" de su libro Hegemonía y estrategia socialista, Ernesto Laclau y Chantal Mouffe nos proporcionan una idea que nos puede guiar en esta línea. Allí, ellos aluden a la disolución de las tres "ilusiones de inmediatez" que ocurrieron en el plano de las ciencias a comienzos de siglo pasado. Estas tres "ilusiones de inmediatez" son el referente, el fenómeno y el signo. Y cada una de ellas dio lugar a una tradición dominante diferente; la filosofía analítica, en el caso del referente, la fenomenología para el caso del fenómeno y el estructuralismo, desarrollado alrededor de la noción de signo. El pasaje en concreto es el siguiente:

En otros trabajos hemos mostrado que la categoría de "discurso" tiene una tradición que remonta a las tres principales corrientes intelectuales del siglo XX: la filosofía analítica, la fenomenología y el estructuralismo. En las tres, el siglo comenzó con una ilusión de inmediatez, de un acceso no mediado discursivamente a las cosas mismas -el referente, el fenómeno y el signo, respectivamente-. En las tres, sin embargo, esta ilusión de inmediatez se disuelve, en un cierto punto, y debe ser reemplazada por una u otra forma de mediación discursiva. Esto es lo que ocurre en la filosofía analítica en la obra del último Wittgenstein, en la fenomenología con la analítica existencial de Heiddeger, y en el estructuralismo con la crítica posestructuralista del signo. Es también, en nuestra opinión, lo que ocurre en la epistemología con la transición verificacionismo/ Popper, Kuhn/Feyerabend, y en el marxismo con la obra de Gramsci, en la que el absolutismo de las identidades de clase del marxismo es reemplazado por identidades hegemónicas constituidas a través de mediaciones no dialécticas (11).

Leyendo este pasaje se encuentra otro motivo para pensar por qué Ginzburg analiza al Wittgenstein de los "juegos del lenguaje" en el ensayo ya aludido, 
que hasta cierto punto es una continuación de temáticas desplegadas en "Spie...", me refiero a "Semejanzas de familia". Es a partir de estas corrientes de pensamiento que la "idea de una legibilidad no inmediata" comienza a validarse en el campo del conocimiento, en un proceso que adquiere relevancia consagratoria hacia las décadas de 1970 y 1980, más allá de las enormes resistencias que encontró ${ }^{8}$. Llama la atención del párrafo también que "lo discursivo" se tornara el signo que anudara aquellas formas de atención y de visualidad. Podemos decir, a partir de esto, que "lo discursivo", como lo entienden Laclau y Mouffe, pasó entonces a demarcar los límites y condiciones del "perímetro de lo insignificante". Aún así, el párrafo anterior no sugiere del todo cómo llegan a asentarse las condiciones de la validación, en otras palabras, de qué modo es que puede explicarse la legitimación de estas transformaciones. La explicación proporcionada por Laclau y Mouffe en el mismo texto para entender estas transformaciones es la siguiente:

Todo cambio sustancial en el contenido óntico de un campo de investigación conduce también a un nuevo paradigma ontológico. Althusser decía que detrás de la filosofía de Platón estaba la matemática griega; detrás del racionalismo del siglo XVII, la física de Galileo, y detrás de la filosofía de Kant, la teoría de Newton. Para plantear el argumento de modo trascendental: la pregunta estrictamente ontológica se interroga acerca de cómo los entes tienen que ser para que la objetividad de un campo específico resulte posible. La ontología implícita en el freudismo, por ejemplo, es diferente e incompatible con la que subyace en un paradigma biologista. Hay un proceso de realimentación mutua e incorporación de nuevos campos de objetos y las categorías ontológicas generales que gobiernan, en un cierto momento, el campo de la objetividad (10).

El "campo de la objetividad" señalado por los autores podemos considerarlo el reverso de lo que hemos venido denominando "perímetro de lo insignificante". Finalmente, es cuando se estabiliza de algún modo el lazo entre lo óntico y lo ontológico en lo referido al "paradigma" emergente cuando las condiciones de legitimación comienzan a generar consensos necesarios para tal objetivo. El lazo no plenamente estabilizado entre lo óntico y lo ontológico es lo que puede explicar las resistencias encontradas por el ensayo que Carlo Ginzburg publicó en 1978. Él mismo consideró en "Reflexiones sobre una hipótesis" que el éxito -lo que incluye la polémica- de su ensayo podía entenderse a partir de un enlace que él buscaba desestabilizar: "Una propuesta teórica muy general, planteada de una manera que ignoraba decididamente, no solo las divisiones entre las disciplinas, sino también las jerarquías etnocéntricas habituales" ("Reflexiones sobre una hipótesis" 8). Por supuesto que hoy, y desde hace bastante tiempo en realidad, aquellas

8 De hecho, en lo relativo a este punto, Carlo Ginzburg señala en su ensayo "Reflexiones sobre una hipótesis" que: "Me daba muy bien cuenta de que había sido capaz de atrapar alguna cosa que estaba flotando en el aire, en la atmósfera de esa época, y que le había dado voz a ciertos temas difusos y que se encontraban en estado de reposo, bajo una forma latente" (8). 
condiciones mencionadas por el historiador italiano mantienen otro sitial en nuestros campos de estudio, modificando así las condiciones de recepción del ensayo. Claro argumento de ello es que, por ejemplo, Giorgio Agamben en su reconsideración del problemático término "paradigma" (que ha recorrido este ensayo), piense al "indicio" -el "spie"- uno de los casos constituyentes de su propuesta conceptual, la signatura:

El indicio representa, pues, el caso ejemplar de una signatura que pone en relación eficaz un objeto, en sí anodino o insignificante, con un hecho (en este caso un delito, pero también, en el caso de Freud, el hecho traumático) y con sujetos (la víctima, el asesino, pero también el autor del cuadro). El "buen Dios" que, según la célebre frase de Warburg -que Ginzburg pone como exergo de su ensayo- se oculta en el detalle, es un signador (97-98).

Podemos pensar que, de hecho, la vinculación de objetos insignificantes con hechos y sujetos constituye uno de los núcleos fuertes de la "democraticidad epistemológica" que, a juicio de Ítalo Calvino, está presente en el trabajo de Carlo Ginzburg. Seguirá siendo nuestro compromiso defenderla, para que aquellos objetos, hechos y sujetos, sobre todo sujetos, que han sido relegados perimetralmente, no vivan ni mueran "sin dejar huellas".

\section{Obras citadas}

Aguirre Rojas, Carlos A. "Indicios, lecturas indiciarias, estrategia indiciaria y saberes populares. Una hipótesis sobre los límites de la racionalidad burguesa moderna". Contrahistorias 7 (2007): 37-62.

Agamben, Giorgio. Signatura rerum. Sobre el método. Buenos Aires: Adriana Hidalgo editora, 2009.

Calvino, Ítalo. "La oreja, el cazador y el chismoso". Contrahistorias 7 (2007): 65-70.

Chartier, Roger. Inscribir y borrar. Cultura escrita y literatura (siglos XI-XVIII). Buenos Aires: Katz, 2006.

Crary, Jonathan. Las técnicas del observador. Visión y modernidad en el siglo XIX. Murcia: CENDEAC, 2008 [1990].

Suspensiones de la percepción. Atención espectáculo y cultura moderna. Madrid: Akal, 2008 [1999].

De los Ríos, Iván. "Introducción. De accidentes, obispos y centauros: Sinesio de Cirene o el placer de la minucia". En: Sinesio de Cirene. Elogio de la calvicie. Madrid: Errata naturae, 2008.

Eco, Umberto; Sebeok, Thomas. El signo de los tres. Barcelona: Lumen, 1989 [1983].

Foucault, Michel. Nietzsche, Freud, Marx. Buenos Aires: El cielo por asalto, 1995.

Giddens, Anthony. Consecuencias de la modernidad. Madrid: Alianza, 1999.

Ginzburg, Carlo. El queso y los gusanos. El cosmos según un molinero del siglo XVI. Buenos Aires: Ariel, 2016 [1976].

"Reflexiones sobre una hipótesis: el paradigma indiciario, veinticinco años después". Contrahistorias 7 (2007): 7-16. 
. "Semejanzas de familia y árboles de familia: dos metáforas cognoscitivas". Contrahistorias 7 (2007): 17-36.

. "Huellas. Raíces de un paradigma indiciario". En Ginzburg, Carlo. Tentativas. Morelia: Universidad Michoacana de San Nicolás de Hidalgo, 2003.

" "Morelli, Freud y Sherlock Holmes: indicios y método científico". En Eco, Umberto; Sebeok, Thomas. El signo de los tres. Barcelona: Lumen, 1989 [1983].

Jay, Martin. Ojos abatidos. La denigración de la visión en el pensamiento francés del siglo XX. Madrid: Akal, 2007 [1993].

Laclau, Ernesto; Mouffe, Chantal. Hegemonía y estrategia socialista. Buenos Aires: Fondo de Cultura Económica, 2004 [1985].

Laclau, Ernesto. Emancipación y diferencia. Buenos Aires: Ariel, 1996.

Ramos, Julio. "Las paradojas del deseo de Flora Tristán". En Latinoamericanismo a contrapelo. Popayán: Universidad del Cauca, 2015.

Rancière, Jacques. El desacuerdo. Política y filosofía. Buenos Aires: Nueva visión, 1996. 
